\title{
EPISTEMOLOGICAL-MOTIVATIONAL BASES OF LITERARY NON-FICTION GENRE AS FACTORS DETERMINING THE LINGUISTIC STRUCTURE OF TEXT
}

\begin{abstract}
This article dwells on epistemological-motivational aspects of the literary non-fiction genre. The general features of memoir literature are examined form the point of view of their epistemological and cognitive aspects. The cognitive and informational specificities of non-fictional narratives are also considered.
\end{abstract}

Keywords: literary nonfiction, genre, linguistic individual, memory, epistemological-motivational basis, linguistic norm, content and expression plan, narrative, description.

Examination of the epistemological bases of texts written in the literary nonfiction genre is of key importance among the contemporary trends in linguistics as the cynosure of the examination captures the linguistic embodiment of the human being as an individual.

In the process of recollecting and reproducing the material retained in memory, authors usually make certain qualitative changes incorporating their world outlook, ideological or value-system predilections.

Authors channel the stream of their sentiments through linguistic norms, which are often structured as a narrative.

Literary nonfiction is an indissoluble unity of form and content. From among the constituent elements of this form of compositions, the linguistic shell of the examined genre plays a particularly important role: it is usually formed through the epistemological-motivational bases of literary nonfiction and helps the authors to create distinctive images and descriptions.

The expression of literary nonfiction hinges on the expressed content (that, which is expressed) and the expressive means (the means through which the expression is mediated), in other words through the content and expression plans, which are demonstrations of the material world.

It is important to point out that whereas in fictional works the authors guide the course of developments themselves on the basis of sequences of events outlined beforehand, memoir-writers compose their stories from the available facts lodged in their memory. The main aim pursued by the literary nonfiction authors is the accurate and consistent reflection of the past reality, events and people, and their interconnections, which may also be conveyed through literary representations. When consigning their memories to writing, memoirists are guided by a single principle - to be authentic and truthful without "sprucing up" the individuals serving as the material of the memories and to write what it held to be true instead. Thus the works of the memoir genre contain valuable information for the adequate cognition of the past times. 
Although the authors of literary nonfiction do not create characters in the same way as in fiction, nonetheless they draw up images that are the live bearers of various phenomena and realities. Whereas the fiction writer is free to choose from among characters, i.e. he or she may, if needed, pencil in protagonists into their writing, thus creating holistic images of the reality, writers of literary nonfiction are constrained in their choice. They may only flesh out the portraits of people with whom their paths have crossed. As noted by V.Belinsky, in this case the author 'does not deal with imaginary characters, instead with people and characters who are familiar to him and in whose company he has lived his life and spend the days of his life' (Terteryan 1948: 428).

It is worth noting that writer of literary nonfiction may ultimately take a subjective stance. The following thought expressed by S.Zorian bears this out: 'Memoirs defy absolute objectivity, and a subjective approach undoubtedly plays a considerable role'. (Zorian 1991: 7.) In this case, the author perceives the model through his or her own impressions. After all, literary nonfiction does not correspond to a representation of life with photographic accuracy. As noted by A.Shirvanzade, there are no and there can be no works presenting images with photographic precision (Shirvanzade 1986: 228). This stance makes W. Saroyan's following observation fully acceptable: 'Memory entails imagination. This is because what you remember does not exactly correspond to what you saw and, since what you saw may have been different, then your recollection contains a degree of imagination. And imagination is the recollected reality'. (Saroyan 1991: 396.)

From the above we may draw the conclusion that the content of literary nonfiction works is constructed by combining various subjective and objective elements. The core of the subjectivity of the non-fiction genre is the system of life values of the author through which he produces his assessments of the people and events of the past.

Memoirists are not at liberty to weave multiple chains of events and phenomena into their texts. They observe the developments through their personal life's window. Here the decisive factors are: which aspects of the reality are taken in by the author, how the facts are processed and how the multiplicity of values is assessed.

In contemporary linguistics, examination of the epistemological bases of nonfictional literary texts as the focus of the analysis is the linguistic rendition of the individual man.

In literature, memoirs and autobiographies are at times categorised as personology. (Neroznak 1996: 112-116.) Here the author-individual is viewed as an individual bringing together personal and social characteristics into one, and who may appear in a world conjured up on his or her own initiative, albeit the composition must have real currents of past reminiscences.

It may be argued that in order to imbue a past event or phenomenon with meaning through linguistic means, 'a certain lowest threshold of mental-emotional activity is required and perceptions, emotions and ideas falling below that threshold cannot be expressed through language. In this case, the given individual's mental and emotional world finds its linguistic expression' (Ibid).

Ghazaros Aghayan stresses in his memoir entitled "The Key Milestones in My Life" that memories are not forgotten only because they recur continuously. 'External impressions are in continuous movement while they pool together in the apex of our being.... An intense excitement is tantamount to causing a storm in that sea' (Aghayan 1963: 424). 
Nonetheless, specialists often present psychological states of mind where the linguistic rendition of memories is difficult to construct due to blurred memory. Armenian prominent general and memoirist I.Baghramyan notes that: 'human memory has many enemies, which albeit slowly but relentlessly undermine it. Among those enemies is the merciless time that wheedles out and destroys grain by grain from the storehouse of memory many remarkable and instructive facts of life as it was lived'. (Baghramyan 1975: 10.)

It is the specificity of human cognition to generalize the life experience. If many encounters with the same person take place at the same location within a certain period of time, then it becomes very difficult to recall the details of those meetings afterwards. Many of the details blend together and are generalised. In fact, there is truth in the statement that memory is a sieve that sifts out the unimportant details and retains what is important or memorable ${ }^{1}$.

When composing literary nonfiction texts, authors naturally tap into different currents of memory. The mechanisms of speech perception and speech production play an important role in the process of the composition of these meta-genres, thus forming the basis for the linguistic thinking pattern.

The process of perception is primarily known as an analytical function and communication of various episodes of an event is thought to be a synthesis. As noted by G. Jahukyan, understanding is first of all analysis, whereas rendering something understandable is primarily a synthesis. (Jahukyan 1974: 20.) This is by and large a distinctive mental system, the highest level of which in this case is the genre-based text plan.

Texts clearly identify the place (the setting), time, characters, the content of speech, which are usually brought together through inter-linkages. It is, however, possible for one of the elements to slip out of the general picture for whatever reason, as at that juncture it may not be viewed to be essential or may be forced out from the spectrum of satisfaction of needs. In this case, the author is not complicit to random presentation, instead, he or she is abstaining from presenting indiscriminately everything that he or she has experienced in their lives. They make a choice, separating the important details from the secondary ones, by setting aside the unimportant and basing the text on what they deem to be the essential and the valuable.

The goal of cognition and consignment to memory by a person involves making a choice. Literary nonfiction writers tend to retain in their memory the essential details, key impressions and not everything that acts on the senses.

In literary nonfiction prose, a key element in the epistemological-motivational process is the agency or the level of activity by the author-memoirist.

Various types of human activity are known to be dominated by different forms of mental activity that may find their reflection in the corresponding actions, movements, emotions, thoughts and images of the individual.

Studies demonstrate that authors of literary nonfiction who engage in a literary dialogue with the reality may be divided into two groups according to their different modes of thinking:

\footnotetext{
${ }^{1}$ At times, in view of certain circumstances, authors of literary nonfiction may choose to omit certain details of the events.
} 
1. Authors, who try to convince the reader about something, disentangle cause-and-effect relationships (chain of causality), to enter into the argumentation domain by forming certain world outlook²;

2. Authors whose emotional-affective faculty is triggered into action. The authors may at times infuse even their descriptions with their emotive states. In fact significant events steeped in emotions are the most vividly recollected memories.

It is worth stressing that literary nonfiction, as a framework of influencing, works through the general communicational medium of perception-understanding-impact, in particular.

It assumes that the author shares observations on different situations in life, personal experience and encounters. It is to be pointed out that the author tells all of this by through engaging with the reader in an open dialogue ${ }^{3}$, which is not to be confounded with the free conversation style or exchange of opinion.

The open dialogue framework is fundamentally different from the everyday colloquial conversation. Here the reality is presented through the example of an individual life and not through the mechanical perception of life. The author communicates impulses to the reader through fiction, influences the reader by securing the reader's approval.

The aim of nonfiction writers is to not only to turn their readers into their adherents but also into participants of the developments. As pointed out by French philosopher and prose writer Jean-Paul Sartre, the author and the reader take on a major responsibility, as 'the world is propped up by the joint efforts by the freedom of the two'. (Sartre 2014: 1)

The open dialogue taking place between the author and the reader creates a new world. They relate to each other through the constituent elements of the same realm of life. This realm of life undoubtedly cannot be identical for everyone. There develops a new dimension between them, despite the shared features. The worlds of either the author or the reader never lose their distinctiveness. As the famous philosopher stressed, in this case, the author's world can only be 'uncovered through the examination by the reader'. (Ibid: 2)

It is evident that the cultural purview of literary nonfiction belongs both to the author and the reader: the reader is often tempted by the author's art of narration.

In the process of recollecting and reproducing the material retained in memory, authors usually make certain qualitative changes unequivocally incorporating their world outlook, ideological or valuesystem predilections. To the contemporary man, the personal "I" is the key axis linking the past, present and future.

All of this supports the assumption that the writing of memoirs, epistles or their linguistic composition is indeed predicated on complex mental-cognitive processes. First of all, the goal of cognition requires the content of the events being reproduced, their sequence, cause-and-effect relationships are to be retained. These should be not only genuine but also compelling. Just like an artist, a memoirist must

\footnotetext{
${ }^{2}$ Convincing through argumentation is the essential element of human cognitive communication through which the reader (listener) develops trust towards the author and a resolve to become the latter's adherent.

${ }^{3}$ According to V.Volkenstein, a sincere dialogue free of obscurities is considered to be open if the wishes and thoughts of the interlocutors are clear and apparent. The opposite of an open dialogue is an indirect dialogue characterised by inherent hidden meaning. (Volkenstein 1969: 70)
} 
be fully familiar with the events, ought to have participated, seen or heard everything recounted, must be able to set apart the important aspects from the secondary details, culling out the latter.

There are also different types of cognitive memory. The demands of cognition of life, the forms of specialist activities of an individual precondition the development, to a greater or lesser degree, of the distinctive features of this or that type of memory. For example, the visual or image-based type of memory frequently occurs in the memoirs of artists, the word-based or abstract type is more characteristic of theorists and scientists, etc.

It is worth stressing that the descriptive elements of language play a particularly important role in the rendition of literary nonfiction materials. A description is fundamentally the author's soliloquy, which is key element of the art of discourse.

Already in the $18^{\text {th }}$ century, the European oratorical tradition differentiated various models of descriptive texts in the form of full description, description of a part of the whole, description of locality and external characteristics (material, form), description of the internal content, etc.

Masters of the literary nonfiction narration take into consideration several factors. First of all, the object being described is of primary importance: it is a portrait or a landscape, an animate being or an event, etc. Secondly, is it narrated with interruptions or as a complete continuum of reminisced facts? And finally the aim of the description is also important as well as the level of the author's participation. From the point of view of the cognitive tasks, it can be mentioned that as a rule, memoirs feature a factual and creative description fusing together artistic, aesthetic and emotional elements.

The descriptions of literary nonfiction texts bring into high relief the key characteristic feature of the person being described (i.e. the real, nonfictional person). Authors with the gift of an artist's subtle perceptiveness portray the external and internal characteristics of the people encountered, depicting those out through accurate and vivid comparisons. These are authentic episodes from where familiar characters, known and unknown people step out and from where engaging, amusing or sad incidents or intimate moments unfold.

Concepts are expressly evident in the literary nonfiction genre. As indicators of the way of thinking, concepts are cultural constructs that take various semantic-structural forms in literary nonfiction writings. Those are not simply about words but also contain essential details determining their communicative value.

We see, hear and perceive various phenomena thanks to the fact that the cognitive, communicative, and linguistic norms of our society assume the given forms of expression. It may be concluded that we are dealing with the targeted or addressee audience of the expression, i.e. to whom the memoirist is addressing.

Thus, the expression of literary nonfiction hinges on the expressed content (that, which is expressed) and the expressive means (the means through which the expression is mediated), in other words through the content and expression plans.

If there is targeted delivery, then this also involves a third party, whose role is to perceive the expression (the person to whom the expression, representation is addressed). 
Content and expression plans are mental reflections and demonstrations of the material world. The expression plan ${ }^{4}$ comprises the expressive means of the material, i.e. the expressive movements (gesticulation, facial expression, etc.), verbal and written speech.

We model the stream of our sensations through language norms thus building the multidimensional construction of the reality. The narrative is a distinctive form of depicting and cognizing the reality (Brooner 2006: 114). This is a writing style, through which 'a story is told'. A narrative is often composed in the first or third person.

A narrative first outlines the overall scheme of the plot and then it is filled out with various details. The characters and events related to them become more clearly outlined in the framework of this intragenre paradigm.

In the content of the texts and various stories within the scope of the examined genre may be permeated with autobiographical elements. In their interpretations of literary nonfiction texts, memoirists construct various scenarios, within the bounds of which the character of the protagonist is revealed and the details of his or her actions are presented.

A narrative is often primarily developed in a context of freedom of actions and naturally contains some interpretative elements. In this case the author aims to produce a compelling interpretation that would encourage the reader to delve ever more intently into every paragraph of the memoir, swaying the reader to accept the engaging element of the memoir.

As a rule, a literary nonfiction story follows a canonical pattern. However, since this canonical structure may not be as engaging in itself, the authors tackle the task of mentally constructing the reality more flexibly in order to inject a sensation of freshness and elegance.

The literary nonfiction narrative seeks to find new ways and means of depicting the reality. And the reader seeks to find novelty, thus indirectly encouraging authors to innovate. It may be argued that the narrative has two functions: firstly, it on the whole presents to the reader the objective reality, and secondly, it compels to look at events and phenomena from a different angle.

A literary nonfiction story is a complete chain of events in itself. These events are interlinked and may lead to one another. Here the author strives to derive an event from another whenever the dividing line between the past and the present becomes apparent.

A conflict is an important element in a narrative. It is not uncommon for the stories to contain a disruption of some norms hidden within their narrative depth. The slightest change in the balance struck between the characters, actions, situations may lead to the conflict precipitating rapid developments. This conflict engages the reader's curiosity and cognitive interest in the given situation.

Dialogues are an important element in a conflict situation, particularly if a mutual understanding is to be reached across disagreements between certain views. Dialogues render the volume of memoir texts more succinct. A dialogue is viewed as an interaction, as a means of recasting the relationships within the scope of everyday life.

Further examples of conflicts are those cases, where the situation is presented through two dissimilar descriptions, each of which is essentially quite compelling and accurate when taken separately.

\footnotetext{
${ }^{4}$ G.Jahukyan calls the study of the expression plan expressionology, distinguishing three key subcategories: study of gestures, study of sounds and study of writing. (Jahukyan 1974: 43)
} 
This makes us think in order to unravel how completely different impressions may result from the same juncture.

Thus, literary nonfiction is an indissoluble unity of form and content. From among the constituent elements of this form of compositions, the linguistic shell of the examined genre plays a particularly important role: it is usually formed through the epistemological-motivational bases of literary nonfiction and helps the authors to create distinctive images and descriptions. The language of the composition is yet another crucially important factor among the elements of the literary nonfiction genre, serving as the one and only, irreplaceable form of depicting and cognizing the reality.

The language of literary nonfiction comprises the word-stock used in the composition, the grammatical structure, the full system of depiction and expression, in a word the full spectrum of language bases used in the construction of the compositions of the genre under examination.

Nonetheless, it is amply evident that the key distinctive feature of the literary nonfiction is that the story is primarily woven from the author's strings of memories. The style and content of the composition, the individual characteristics of the author, etc. also play an important role. All of these factors may indeed have an impact on the language of the literary nonfiction text at hand, introducing unique features of expression and presentation.

There is another feature of memoir-writing that may add to the significance of the current analysis. Specialists note that writing memoirs may have a therapeutic influence. Armenian writer Vahram Alazan followed the advice of neuropsychologist Professor Groy to take up memoir writing during an exacerbated period of illness, which calmed down his overstrained nerves, restoring his health ${ }^{5}$. The writer made a note of this in his reminiscences.

American psychologist Jerry Waxler kept a diary since early childhood and kept a record of his thoughts. Many years later the psychologist recollected how the torrent of words flowing out onto paper brought calmness to his unruly thoughts and instilled peace in him. The psychologist finds that when one writes from the bottom of one's heart, this helps with self-discovery and helps to see things more clearly. According to him, memoirs of famous people may stir something like a revolution in the wider society. By writing the story of a life, it is possible in essence to see the limits of the given person's life, to understand his or her essence and mind-set. J.Waxler is of the opinion that jumbled thoughts are in actual fact formed in memoirs just like mosaic pieces. 'Writing memoirs is form of treatment,' concludes the psychologist (Waxler 2013: 1).

Although discussion of memoir therapy is outside the scope of this paper, a brief reference to it may serve to spawn new ideas and studies.

\section{REFERENCES}

Terteryan, A. (1948). Belinski (Belinsky). Er\&an: Er\&ani hamalsarani hratarakchut'yun.

\footnotetext{
${ }^{5}$ This utilises the expulsion mechanism, which according to S. Freud is one of the protective mechanisms of the ego, thanks to which saturated contents, memories, etc. are pushed out of consciousness into the subconscious sphere. Freud held the opinion that the expelled thoughts are not rendered inactive in the unconscious layers and continuously require mental energy for outbursts to be prevented (Freud 2010: 27).
} 
Zoryan, S. (1991). Husheri girq (Book of Reminiscences). Er\&an: Hayastan hratrarakchutyun.

Shirvanzade, A. (1986). Raffin jhamanakakicneri husherum (Raffi in the Reminiscences of His Contemporaries). Er\&an: HSSH GA hratarakchut'yun.

Saroyan, W. (1991). Y'ntir erker, hator 4 (Selected Works, Volume 4). Er\&an: Nairi hratarakchut'yun.

Neroznak, V.P. (1996). Lingvisticheskaya personologia: k opredeleniyu statusa distsypluny. Yazyk, Poetika,

Perevod (Linguistic Personology: Towards Defining the Disciplinary Status. Language, Poetry, Translation). Moskva: Izdatel'stvo MGU.

Aghayan, Gh. (1963). Im kyanqi glxavor depqery (The Key Milestones in My Life). Er\&an: Haypethrat.

Baghramyan, I. (1975). Ayspes e sksvel paterazmy (This Is How the War Started). Er\&an: Hayastan hratarakchut'yun.

Jahukyan, G. (1974). Jhamanakakic hayereni tesutyan himunqner (The Fundamentals of the Theory of Contemporary Armenian). Er\&an: HSSH GA hrararakchut'yun.

Volkenstein, V. (1969). Dramaturgiya (Playwriting). Moskva: Sovetskii pisatel.

Sartre, J. (2014). Inch e grakanut'yuny (What is Literature?): http://lit-bridge.com/tag:

Brooner, J. (2006). Kul'tura obrazovaniya (Educa-

tional Studies). Moskva: Prosveshchenie.

Freud, S. (2010). Hogeverluc'ut'yan nerac'ut'yun (Introduction to Psychoanalysis). Er\&an: Zangak-97 hratarakchut'yun.

Waxler, J. (2013). Memoir Revolution: http://meorywritersnetwork.com/blog/ 